\title{
Detection of Breast Cancer: Knowledge, Attitude, and Practice of Family Health Strategy Women
}

\author{
Rosy Denyse Pinheiro de Oliveira ${ }^{1}$ - Míria Conceição Lavinas Santos ${ }^{1}$. \\ Camila Brasil Moreira ${ }^{1}$ - Ana Fátima Carvalho Fernandes ${ }^{1}$
}

(C) American Association for Cancer Education 2017

\begin{abstract}
In rural area, control of breast cancer is related to health promotion and early diagnosis, which includes knowledge, awareness, and stimulating behavioral change, emphasizing screening for disease. The present study was developed to assess the knowledge, attitude, and practice of rural women about early detection of breast cancer in the Primary Health Care Centre. This is a cross-sectional study in a Primary Health Care Centre with 243 rural women participating in the public health service. Data collection was made by a self-administered questionnaire which included sociodemographic characteristics, questions on breast cancer risk factors, screening, and diagnostic methods. Marks were attributed to each question and calculated for each section. Participants fell in three categories of knowledge, attitude, and practice: appropriate, regular and inappropriate. Knowledge, attitude, and practice of early detection methods were considered especially appropriate for those rural women with education and higher economic level, but inadequate responses to such methods were still significant. It is noted that there is still a significant number of rural women who do not have basic knowledge regarding early detection methods of breast cancer, contributing to the non-realization of these methods, as its advocates.
\end{abstract}

Keywords Breast cancer - Breast cancer screening · Early diagnosis $\cdot$ Knowledge, attitude and practice $\cdot$ Rural woman

Camila Brasil Moreira

camilabrasil@alu.ufc.br

1 Department of Nursing, Federal University of Ceará, Alexandre Baraúna Street, 1115, Fortaleza 60430-160, Brazil

\section{Introduction}

In Brazil, breast cancer mortality accompanies the global results, representing the leading cause of death by cancer in the female population, accounting for 13.345 deaths $[1,2]$.

Breast cancer presents a satisfying prognosis. The great impasse is the late diagnosis into rural woman, which reflects in a high rate of mortality [3].

One of the health promotion actions directed to the control of breast cancer is the screening program in the target population. The currently public health mammography screening program in Brazil is focused on woman aged 50-69 years who have received a bilateral mammography within the past 2 years, but all woman aged 35 years should obtain the first mammogram to get breast imaging control and those who are presenting a high risk for breast cancer should start the mammography screening in this age too [4]. According to data from public sources in 2013, about 2.5 million mammograms are held in Health Unique System that means 34\% in terms of the estimated national coverage of mammography screening [5].

The Primary Health Care Centre (PHCC) also develops various actions related to early detection, and health education about screening, identification of women belonging to the target group for mammography, realization of oncotic cytology, in which the Clinical Breast Exam (CBE) is also performed, with active search for defaulting and planning actions according to the results [6].

In rural area, control of breast cancer is related to health promotion and early diagnosis, which includes knowledge, awareness, and stimulating behavioral change, emphasizing screening for disease [7].

Starting from the assumption that the sociodemographic profile of the rural clientele in the basic health units contributes to adherence to early detection actions of the disease, this research was developed in order to assess the women's 
knowledge, attitude, and practice about early detection of breast cancer in the PHCC.

\section{Methods}

This is a cross-sectional study associated with the KAP (knowledge, attitude, and practice) survey for early detection methods of breast cancer, conducted with women attending in the PHCC [8], located in a rural area, the municipality of Capistrano, situated in Maciço de Baturité, in the North of Ceará State.

The PHCC provides specialty care in the areas of pediatrics, gynecology, obstetrics, and dentistry. Health care at the health center emphasizes preventive and screening services for communicable and noncommunicable diseases such as cancer, obesity, diabetes, and cardiovascular diseases. Furthermore, the PHCC is the first point of contact in the health care system and initiate referrals to the local and regional hospitals whenever necessary.

The population of interest for the survey was loosely defined, so a random sampling method could not be used, and therefore the availability sampling, also known as convenience sampling, was used. All woman found in the PHCC ranging in age from 35 to 69 years old between May and July 2014 were approached to participate in the study. Accordingly, the data for this study was collected from 243 rural women attending in the PHCC.

For the characterization of the group, a self-administered questionnaire containing the sociodemographic questions, questions on knowledge, attitude and practice on breast cancer screening, diagnosis, and risk factors. The procedure consisted of, firstly, an explanation of the study purpose, then we obtained the signed consent of women who agree to participate. Thereafter, they were given the self-administered questionnaire; however, when needed, a trained interviewer gave ongoing assistance in order to avoid measurement error.

We asked questions about risk factors, breast cancer clinical signs, diagnosis, and screening methods for breast cancer which purpose was to assess the knowledge of participants. To evaluate the attitude, we sought what the participants thought about the effectiveness of breast cancer screening methods. To assess the practice, we asked if the participants do breast selfexamination (BSE), if they have clinical breast examination regularly, and if they take breast mammogram for screening.

For the classification of responses on knowledge, attitude, and practice, we used the following classification: Regarding knowledge, it was considered appropriate for women who got 6 to 9 points and inappropriate from 0 to 5 points. Regarding the attitude, we considered appropriate 3 to 4 points and inappropriate from 0 to 2 points. Regarding the practice, it was considered appropriate for those who got at least 3 points and inappropriate from 0 to 2 points.
Since Brazil is a country where the economic divergence is vast, the government created in 2013 the Brazil Economic Classification Criterion (BECC) of the Brazilian Association of Research Company (BARC) in attempt to standardize the Brazil economy profile. For this reason, a questionnaire corresponding to this classification was also applied in order to obtain consistent sociodemographic profile [9].

Data were compiled and analyzed by means of the Statistical Package for the Social Sciences program, version 21.0. The association between the adequacy of knowledge, attitude, and practice regarding the methods of early detection of breast cancer, and some sociodemographic variables and/or clinical-gynecological variables, was held through the Chisquare test, with a significance level of $5 \%$ to test the differences between the proportions.

The experimental protocols were approved by the appropriate institutional review committee and meet the guidelines of their responsible governmental agency. The study was authorized by the Health's Secretary of Capistrano/Ceará and by the Research Ethics Committee of the Federal University of Ceará (Protocol n. 615.025), and informed consent was obtained from all individual participants included in this study.

\section{Results}

The initial sample consisted of 255 women, belonging to six rural areas of operation of the PHCC, ranging in age from 35 to 69 years old. Among them, 96 (37.6\%) were aged between 40 and 49 and 147 (57.6\%) between 50 and 69. Despite having been interviewed $12(4.8 \%$ ) women within the range of 35 to 39 years, these have been deleted and did not add to study sample due to not presenting a high risk for breast cancer, which is what the Ministry of Health $(\mathrm{MOH})$ provides for tracking. For this reason, this value did not influence on the final sample data. The final sample consisted of 243 women, and their sociodemographic profile was represented on Table 1.

The overall analysis of knowledge and attitude of participants was classified as appropriate $236(97.0 \%)$, in contrast the practice was classified as inappropriate $170(70.1 \%)$ (Table 2).

Regarding receipt of information about breast cancer, most of them, $82(47.4 \%)$, regarding the nurses were the main responsible for the transmission of information on breast cancer.

When inquired about the knowledge of the meaning and timing of mammography, emphasizing that were considered appropriate responses only those which correctly answered the significance and frequency.

About women who have asked their doctor to request the mammogram are those who have never requested it; 55 (41.3\%) women reported that they trust the doctor who knows the best time to apply for the exam, and 40 (30.1\%) women 
Table 1 Sociodemographic profile of participants

\begin{tabular}{|c|c|}
\hline Variables & $n=243(\%)$ \\
\hline \multicolumn{2}{|c|}{ Age $(n=51.9$ years old $)$} \\
\hline Up to 50 years old & $96(39.5)$ \\
\hline Over 50 years old & $147(60.5)$ \\
\hline \multicolumn{2}{|l|}{ Education } \\
\hline Illiterate & $78(32.1 \%)$ \\
\hline Elementary school & $86(43.7 \%)$ \\
\hline High school & $40(16.5 \%)$ \\
\hline Higher education & $19(7.8 \%)$ \\
\hline \multicolumn{2}{|l|}{ Social level } \\
\hline $\mathrm{A}^{\mathrm{a}}$ & $1(0.004 \%)$ \\
\hline $\mathrm{B}^{\mathrm{b}}$ & $23(9.5 \%)$ \\
\hline $\mathrm{C}^{\mathrm{c}}$ & $94(38.7 \%)$ \\
\hline$D^{d}$ & $125(51.4 \%)$ \\
\hline \multicolumn{2}{|c|}{$\begin{array}{l}{ }^{\mathrm{a}} \text { Economic level corresponding to } 35-41 \\
\text { points, according to BECC }\end{array}$} \\
\hline \multicolumn{2}{|c|}{$\begin{array}{l}{ }^{\mathrm{b}} \text { Economic level corresponding to } 23-34 \\
\text { points, according to BECC }\end{array}$} \\
\hline \multicolumn{2}{|c|}{$\begin{array}{l}{ }^{\mathrm{c}} \text { Economic level corresponding to } 14-22 \\
\text { points, according to BECC }\end{array}$} \\
\hline $\begin{array}{l}{ }^{\mathrm{d}} \text { Economic level corr } \\
\text { points, according to B }\end{array}$ & ding to $0-13$ \\
\hline
\end{tabular}

reported lack of knowledge regarding the need of examination.

More detailed analysis was used to assess the association between knowledge, attitude, and practice of woman. By associating the results, Table 3 presents the appropriate knowledge, attitude, and practice regarding the methods of early detection of breast cancer and its association with the analyzed sociodemographic characteristics.

Significantly higher proportions of attitude and appropriate practice were identified in women over 50 years old and belonging to higher social levels.

Table 4 presents the inappropriate knowledge, attitude, and practice about early detection methods of breast cancer and sociodemographic characteristics.

It is observed that education is directly related to knowledge, since a significant number of rural women, with regular and inadequate responses, presented lower level of education. Regarding knowledge associated with age, and those who gave considered suitable answers, there was no difference between those women more or less than 50 years old. However, the presence of inappropriate responses was higher between women over 50 years old.

\section{Discussion}

As it was presented by the study, education is directly related to knowledge and attitude, since a significant number of rural
Table 2 Knowledge, attitude, and practice of participants

\begin{tabular}{|c|c|}
\hline Variables & $n=243(\%)$ \\
\hline \multicolumn{2}{|c|}{ Knowledge } \\
\hline \multicolumn{2}{|c|}{ Receive information about breast cancer } \\
\hline No & $70(28.8 \%)$ \\
\hline Yes & $173(71.2 \%)$ \\
\hline \multicolumn{2}{|c|}{ Know the meaning and timing of mammography } \\
\hline No & $98(40.3 \%)$ \\
\hline Yes & $145(59.7 \%)$ \\
\hline \multicolumn{2}{|c|}{ Know about $\mathrm{SBE}$ and $\mathrm{CBE}$} \\
\hline No & $199(82 \%)$ \\
\hline Yes & $44(18 \%)$ \\
\hline \multicolumn{2}{|c|}{ Know about risk factors } \\
\hline No & $184(75.8 \%)$ \\
\hline Yes & $59(24.8 \%)$ \\
\hline \multicolumn{2}{|c|}{ Know about breast cancer manifestations } \\
\hline No & $103(42.4 \%)$ \\
\hline Yes & $140(57.6 \%)$ \\
\hline \multicolumn{2}{|l|}{ Attitude } \\
\hline \multicolumn{2}{|c|}{ Desire to participate in the guidelines } \\
\hline No & $62(25.5 \%)$ \\
\hline Yes & $126(51.9 \%)$ \\
\hline \multicolumn{2}{|c|}{ Request mammogram } \\
\hline No & $133(54.7 \%)$ \\
\hline Yes & $110(45.3 \%)$ \\
\hline \multicolumn{2}{|l|}{ Practice } \\
\hline \multicolumn{2}{|l|}{ SBE } \\
\hline No & $151(62.1 \%)$ \\
\hline Yes & $92(37.9 \%)$ \\
\hline \multicolumn{2}{|l|}{ CBE } \\
\hline No & $124(51 \%)$ \\
\hline Yes & $119(49 \%)$ \\
\hline \multicolumn{2}{|c|}{ Mammogram } \\
\hline No & $149(61.3 \%)$ \\
\hline Yes & $94(58.7 \%)$ \\
\hline \multicolumn{2}{|l|}{ Smoke } \\
\hline No & $210(86.4 \%)$ \\
\hline Yes & $33(13.6 \%)$ \\
\hline \multicolumn{2}{|c|}{ Alcoholism } \\
\hline No & $217(89.3 \%)$ \\
\hline Yes & $26(10.7 \%)$ \\
\hline
\end{tabular}

women with inappropriate responses presented lower level of education.

Studies related to early detection of breast cancer have also confirmed that knowledge, and even the practice of tracking methods, maintain a connection with education level. With regard to the $\mathrm{CBE}$, the more time spent in school, the greater the realization of it [10]. 
Table 3 Relationship between appropriate knowledge, attitude, and practice

\begin{tabular}{|c|c|c|c|c|c|c|}
\hline \multirow[t]{2}{*}{ Variables } & \multicolumn{2}{|c|}{ Appropriate knowledge } & \multicolumn{2}{|c|}{ Appropriate attitude } & \multicolumn{2}{|c|}{ Appropriate practice } \\
\hline & $N(\%)$ & $p$ & $N(\%)$ & $p$ & $N(\%)$ & $p$ \\
\hline Age & & 0.108 & & 0.320 & & 0.032 \\
\hline Up to 50 years old & $19(17.4)$ & & $43(39.4)$ & & $14(12.8)$ & \\
\hline Over 50 years old & $19(14.2)$ & & $52(38.8)$ & & $32(23.9)$ & \\
\hline Education & & 0.001 & & 0.001 & & 0.493 \\
\hline Illiterate & $2(2.6)$ & & $19(24.7)$ & & $14(18.2)$ & \\
\hline Incomplete elementary school & $8(10.8)$ & & $23(31.1)$ & & $11(14.9)$ & \\
\hline Complete elementary school & $3(9.4)$ & & $17(53.1)$ & & $6(18.8)$ & \\
\hline High school & $18(43.9)$ & & $24(58.5)$ & & $10(24.4)$ & \\
\hline Higher education & $7(36.8)$ & & $12(63.2)$ & & $5(26.3)$ & \\
\hline Social level & & 0.001 & & 0.077 & & 0.534 \\
\hline $\mathrm{A}^{\mathrm{a}}$ & $1(100.0)$ & & $1(100.0)$ & & $1(100.0)$ & \\
\hline $\mathrm{B}^{\mathrm{b}}$ & $19(75.0)$ & & $12(75.0)$ & & $7(25.0)$ & \\
\hline $\mathrm{C}^{\mathrm{c}}$ & $21(17.2)$ & & $48(55.2)$ & & $15(17.2)$ & \\
\hline$D^{d}$ & $5(4.5)$ & & $34(27.3)$ & & $23(19.1)$ & \\
\hline
\end{tabular}

${ }^{a}$ Economic level corresponding to 35-41 points, according to BECC

${ }^{\mathrm{b}}$ Economic level corresponding to 23-34 points, according to BECC

${ }^{\mathrm{c}}$ Economic level corresponding to 14-22 points, according to BECC

${ }^{\mathrm{d}}$ Economic level corresponding to $0-13$ points, according to BECC
A study in Teresina also states that the lower the level of education and household income, the lower the adherence to conducting screening tests. Failure to perform mammography among illiterate presented a percentage 6.89 times greater than among those who had completed higher education, and the number of those who had an income of less than two minimum wages was 5.97 times higher than those who earned above six minimum wages [11].
Table 4 Relationship between inappropriate knowledge, attitude, and practice

\begin{tabular}{|c|c|c|c|c|c|c|}
\hline \multirow[t]{2}{*}{ Variables } & \multicolumn{2}{|c|}{$\begin{array}{l}\text { Inappropriate } \\
\text { knowledge }\end{array}$} & \multicolumn{2}{|c|}{ Inappropriate attitude } & \multicolumn{2}{|c|}{ Inappropriate practice } \\
\hline & $N(\%)$ & $p$ & $N(\%)$ & $p$ & $N(\%)$ & $p$ \\
\hline Age & & 0.108 & & 0.320 & & 0.032 \\
\hline Up to 50 years old & $39(35.8)$ & & $28(25.7)$ & & $49(45.0)$ & \\
\hline Over 50 years old & $66(49.3)$ & & $45(33.6)$ & & $63(47.0)$ & \\
\hline Education & & 0.001 & & 0.001 & & 0.493 \\
\hline Illiterate & $52(67.5)$ & & $36(46.8)$ & & $40(51.9)$ & \\
\hline Incomplete elementary school & $34(45.9)$ & & $21(28.4)$ & & $38(51.4)$ & \\
\hline Complete elementary school & $11(34.4)$ & & $5(15.6)$ & & $15(46.9)$ & \\
\hline High school & $7(17.1)$ & & $8(19.5)$ & & $13(31.7)$ & \\
\hline Higher education & $1(5.3)$ & & $3(15.8)$ & & $6(31.6)$ & \\
\hline Social Level & & 0.001 & & 0.077 & & 0.534 \\
\hline $\mathrm{A}^{\mathrm{a}}$ & $0(0.0)$ & & $0(0.0)$ & & $0(0.0)$ & \\
\hline $\mathrm{B}^{\mathrm{b}}$ & $4(21.1)$ & & $4(15.8)$ & & $8(36.8)$ & \\
\hline $\mathrm{C}^{\mathrm{c}}$ & $32(36.4)$ & & $23(25.8)$ & & $43(47.0)$ & \\
\hline$D^{d}$ & $69(54.5)$ & & $46(38.2)$ & & $61(50.9)$ & \\
\hline
\end{tabular}

${ }^{\text {a }}$ Economic level corresponding to 35-41 points, according to BECC

${ }^{\mathrm{b}}$ Economic level corresponding to 23-34 points, according to BECC

${ }^{\mathrm{c}}$ Economic level corresponding to 14-22 points, according to BECC

${ }^{\mathrm{d}}$ Economic level corresponding to $0-13$ points, according to $\mathrm{BECC}$ 
According to economy level, it was also visible that the influence of the most appropriate answers are related to higher social levels and vice versa.

As for the BECC, some early detection methods are directly related to economic level. Studies show that women belonging to lower economic level are those who perform less mammography, interfering with preventive measures. This is also seen in the SBE and the CBE. These studies show that the higher the educational level and income, more satisfactory are secondary prevention actions, resulting in an early diagnosis and mortality reduction [12].

Studies also suggest that there is misinformation about breast cancer. Lack clarification of issues related to the disease is adding to the difficulties of examination request and achievement related to the diagnosis of that disease [13].

With regard to Brazil, for many years, there were means to encourage the SBE, but it is still discreet in relation to mammography, which limits the knowledge of this examination as a screening method [14].

There is no point in talking or reading brochures or books about something that they do not even know what means. What drew attention was also that among all respondents who defined what the clinical breast exam means, despite knowing the concept, they related it only to the examination of gynecological prevention.

The CBE, another screening method, was also researched. When we asked the difference between SBE and CBE, many rural women said they did not know it, and many also said they knew what self-examination was, but did not know what the clinical examination was. To get an adequate response, they should meet the two exams, as they should be differentiated.

Corroborating the results, another study shows that despite the CBE be recommended since 2004 for women 40-69 years of age, on an annual basis, what we observed is that the vast majority of them do not even know what the breasts clinical examination means [15].

It requires the transmission of information by professionals so that rural women can acquire knowledge, changing their behavior and thus their attitudes. Disease prevention and reduction of risk factors are related to health education actions [16].

As regards, the breast cancer and early detection methods, the results are in agreement with other studies that indicate lack of knowledge about the disease, as well as with respect to the target population for mammography and the time interval that this examination should be performed [14].

In a study in the municipalities of Rio Grande do Sul State, it was also noted the need for further guidance about the screening methods for breast cancer, especially in those municipalities which do not yet provide mammography [17].

Among the clinical manifestations of breast cancer, there was a significant number of rural women who could not answer questions on it.
The lack of knowledge of the clinical manifestations complicates the search for service and, therefore, the lack of early diagnosis. Added to this, the fact that some doctors consider normal some suggestive changes of cancer and the difficulty for women to schedule appointments, tests, and referrals, are delaying the diagnosis [18].

Although breast cancer is a priority in public policy, many health professionals still unaware tracking actions and are based on complaints and conducts for care. Studies also show that even the professionals involved in primary care are unaware of protocols defined by the Ministry of Health, hindering the transmission of important information to the population [19].

Another important factor is that most rural women, who never requested mammography to a professional, exerting their self-care, report that they wait for the professional to request it, because they believe that when it will be the right time, then the doctor will ask for the exam.

A study carried out in Teresina also shows the nonrealization of mammography is linked to the lack of request by the medical professional, as the main cause, followed by the absence of clinical manifestations [12].

As for their lifestyle, smoking habits and alcohol consumption were held by the minority of women. This aspect was also not common in another study conducted in Brazil, in the State of Maranhão, held with 552 women, where only $8.2 \%$ were smokers and $8.7 \%$ were using alcohol [20].

\section{Conclusion}

As presented in the tables related to knowledge, attitude, and practice, it was observed that, despite the actions taken for the early detection of breast cancer in the PHCC, the availability of existing screening tests and the transmission of information through professional and media with respect to the problems of this type of cancer, the knowledge, attitude, and practice of rural women users of the PHCC are not yet satisfactory, reflecting the need for better targeting of actions for that matter.

It was found in this study that rural women accompanied in health facilities, even having a follow-up by primary care, still do not know satisfactorily the risk factors, clinical manifestations, and frequency of screening tests for breast cancer, which influences negatively their quality of life and the survival rates of people with this kind of disease.

Among the explanatory variables, it was realized that schooling interferes with answers related to knowledge and attitude of rural women of the target population, in relation to the early detection of breast cancer, as well as the economic level is related to the guidance on tracking methods.

During the interviews, the major limitation referred to the fact that sometimes we did not find the selected sample, even following the schedule of the PHCC, because sometimes there were unforeseen, in which professionals did not go to work 
and, therefore, most people returned home, as well as changes in the planned schedule, requiring several trips to the selected sites to get the results.

\section{References}

1. Faria SS, Freitas-Junior R, Silva PL (2013) Prevalência e Perfil Clínico da Síndrome de Mama Fantasma: revisão integrativa. Rev Bras Cancerol 59:113-122. doi:10.1590/SO100720320150005353

2. Instituto Nacional do Câncer (2016) Estimativa do 2016: Incidência de Câncer no Brasil. Inca, Rio de Janeiro, p 2016 http://www.inca. gov.br/estimativa/2016/estimativa-2016-v11.pdf

3. Gomes LMX, Alves MC, Santos TB, de Andrade-Barbosa TL, de Souza LMT (2012) Conhecimento e prática do autoexame das mamas por acadêmicas de enfermagem. Rev Cubana Enfermer 28:465-4730. doi:10.1590/S0080-62342009000400023

4. Instituto Nacional do Câncer (2015) Secretaria de Ciência, Tecnologia e Insumos Estratégicos. Diretrizes para detecção precoce do câncer de mama. Brasília: Inca

5. Fernandes AFC (2011) Enfermagem e as ações na promoção da saúde mamária. Rev Rene 12:449. doi:10.1590/S008062342009000400023

6. da Saúde M (2011) Programa nacional de controle do câncer do colo do útero e de mama: proposta de fortalecimento das ações de prevenção, diagnóstico e tratamento do câncer de colo do útero e de mama. Inca, Rio de Janeiro, p 2011

7. Silva ARS, Alves ERP, Barros MBSC, Bushatsky M, Souto CMMR, dos Filho SF, Simão A (2011) Educação em saúde para deteccão precoce do câncer de mama. Rev Rene 12:952-959. doi: 10.17058/reci.v5i4.5458

8. Warwick DP, Linninger AC (1975) The sample survey: theory and practice. McGraw Hill, New York, pp 4-19

9. Associação Brasileira de Empresas de Pesquisa (BR) (2013) Critério de Classificação Econômica Brasil. Retrieve from: http:// www.abep.org/new/criterioBrasil.aspx

10. da Pamella Araújo S, da Silva Riul S (2011) Câncer de mama: fatores de risco e detecção precoce. Rev Bras Enferm 64:10161021. doi:10.1590/S0034-71672011000600005

11. Lages RB, Oliveira G d P, Filho S, Morais V, Nogueira FM, Teles JBM, Vieira SC (2012) Desigualdades associadas à não realização de mamografia na zona urbana de Teresina-Piauí-Brasil, 20102011. Rev bras epidemiol 15:737-747. doi:10.1590/S1415790X2012000400006

12. de Matos JC, Pelloso SM, de Barros Carvalho MD (2011) Fatores associados à realização da prevenção secundária do câncer de mama no Município de Maringá, Paraná, Brasil. Cad Saúde Pública 27:888-898. doi:10.1590/S0102-311X2011000500007

13. Oshiro M d L, Bergmann A, da Silva RG, da Costa KC, Travaim IEB, da Silva GB, Thuler LCS (2014) Câncer de mama avançado como evento sentinela para avaliação do programa de detecção precoce do câncer de mama no Centro-Oeste do Brasil. Rev Bras Cancerol 60:15-23

14. Lourenço TS, Mauad EC, da Costa Vieira RA (2013) Barreiras no rastreamento do câncer de mama e o papel da enfermagem: revisão integrativa. Rev bras Enferm 66:585-591. doi:10.1590/S003471672013000400018

15. Silva Gulnar AE, Bustamante-Teixeira MT, Aquino EML, Tomazelli JG, Dos-Santos-Silva I (2014) Acesso à detecção precoce do câncer de mama no Sistema Único de Saúde: uma análise a partir dos dados do Sistema de Informações em Saúde. Cad Saúde Pública 30:1537-1550. doi:10.1590/0102$311 \mathrm{X} 00156513$

16. de Oliveira MS, Santos MCL, de Almeida PC, Panobianco MS, Fernandes AFC (2012) Evaluation of an educational handbook as a knowledge-acquisition strategy for mastectomized women. Rev Latino-Am Enfermagem 20:668-676. doi:10.1590/S010411692012000400006

17. Renck DV, Barros F, Domingues MR, Gonzalez MC, Sclowitz ML, Caputo EL, Gomes L d M (2014) Equidade no acesso ao rastreamento mamográfico do câncer de mama com intervenção de mamógrafo móvel no sul do Rio Grande do Sul, Brasil. Cad. Saúde Pública 30:88-96. doi:10.1590/0102-311X00017113

18. da Rosa LM, Radünz V (2013) Do sintoma ao tratamento adjuvante da mulher com câncer de mama. Rev Texto \& Contexto 22:713721. doi:10.1590/S0104-07072013000300018

19. de Moraes DC, de Almeida AM, de Figueiredo EN, de Loyola EAC, Panobianco MS (2016) Opportunistic screening actions for breast cancer performed by nurses working in primary health care. Rev esc enferm USP 50:14-21. doi:10.1590/S0080623420160000100002

20. Brito LMO, da Costa Chein MB, Brito LGO, Amorim ÂMM, Marana HRC (2010) Conhecimento, prática e atitude sobre o autoexame das mamas de mulheres de uma cidade do Nordeste do Brasil. Rev Bras Ginecol Obstet 32:241-246. doi:10.1590/ S0100-72032010000500007 